\title{
Toward an Inclusive Teacher Education Program
}

\author{
Nan Kurz and Peter V. Paul \\ The Ohio State University
}

\begin{abstract}
Although definitions of high quality teaching vary considerably, a good teacher capitalizes on the strengths of every student. Yet, novice teachers struggle to identify all students' abilities. Many teachers describe inclusion practices as just another obstacle encountered in the classroom. Scholars seek to identify ways of changing this burden of inclusion mindset to a welcoming/enriching notion aligned with social justice agendas. In this paper, we discuss the need for pre-service teachers to enter the classroom with the disposition to focus on individual strengths and to understand how the diversity of students' abilities and backgrounds contributes to the subjective well-being of the student population.
\end{abstract}

Teachers must conceptualize the uniqueness of every child and celebrate difference as a natural state of affairs. Only when students feel valued and accepted will they succeed and envision school as a place of possible ascent. Too often, schools perceive of children in ways that are destructive where student differences become deficits (Shields, Bishop, \& Mazawi, 2005). Implicit and explicit structures in teacher education support and encourage such pathologizing practices in which pre-service teachers learn to identify diverse needs of students and strategize over ways to correct or save the students. Using the theoretical framework of positive psychology (Seligman \& Csikszentmihalyi, 2000), questions arise on how to address the process of viewing students with disabilities as deficient. How can educators begin to change their conceptions of students with disabilities to fully integrate them into the school community? How can teacher educators move away from the discourses surrounding deficit thinking? This last question is the focus of this paper. In addition to discussing the issue, we will provide recommendations for teacher educators to remodel existing structures and include all students.

Positive psychology seeks to explore and explain optimal learning environments (Seligman \& Csikszentmihalyi, 2000). Analyzing positive emotions, traits, and institutions, positive psychologists attempt to identify situations where humans thrive and flourish (Peterson \& Seligman, 2004). In examining the classroom context, teacher educators can use positive psychology techniques to assist novice educators in developing the necessary academic knowledge and a set of character strengths (e.g., wisdom, courage, humanity, justice, temperance, and transcendence) that can maximize the positive qualities

Nan Kurz is a doctoral student at The Ohio State University in The College of Education's Department of Policy and Leadership.

Peter Paul is a Professor in Access Education in The College of Education, Department of Teaching and Learning, The Ohio State University. 
of students, classrooms, schools, and communities. In essence, novice classroom teachers need to learn to use facilitative techniques (e.g., inquiry approaches, differentiated instruction, positive behavior supports) to assist their students in learning academic content and growing socially and emotionally. The proposed outcome is an inclusive environment in which student differences are appreciated and celebrated.

\section{Diversity of Twenty-first Century Classrooms}

In many countries, diversity is in constant flux. When considering urban student populations, Ladson-Billings (2001) comments: "Not only are students of different races and ethnicities, but there are students whose parents are incarcerated or drug-addicted, whose parents have never held a steady job, whose parents themselves are children" (p. 14). Comparing demographic data between teachers and students, significant differences appear in the United States. Gay and Howard (2000) report that $86 \%$ of American pre-service teachers are from European backgrounds. While ethnic background has been investigated, to date, research on the frequency of prospective and practicing teachers with disabilities has not been completed. Furthermore, it is predicted that by the year 2020, student populations will include predominately non-white students from a range of socio-economic backgrounds (Gay \& Howard, 2000; NCES, 2005); if the trend of European background teachers continues, the great teacher-student mismatch will persist. Such a mismatch between student and teacher demographics poses challenges for teachers to meet the needs of so many diverse learners (Milner, 2005).

The mismatch between student and teacher backgrounds accounts for differential expectations as teachers struggle to understand the many backgrounds and abilities of the students in their classrooms (Cockrell, Placier, Cockrell, \& Middleton, 1999; Saft \& Pianta, 2001). As Saft and Pianta (2001) found, the greater the difference in background between the student and teacher, the more likely students were to be referred for counseling. Such findings suggest that a level of comfort develops between those with similar backgrounds. When students and teachers have similar backgrounds, they tend to be more willing to find strategies within the classroom to facilitate teacher-student interactions.

Most educators envision twenty-first century schools as learning communities upon which student differences are appreciated and capitalized. Effective teacher educators must respond by preparing prospective and practicing teachers with the knowledge, skills, and dispositions aligned with maximizing the learning of all students. In fact, "the myth of the average learner has been shattered and teachers are recognizing the need to individualize and honor the unique profiles of all students" (Kluth, Straut, \& Biklen, 2003, p.19).

When topics surrounding the diversity of students arise, conceptions and discussions often fail to include students with disabilities. In the United States, the National Council for the Accreditation of Teacher Education (2002) defines diversity as "differences among groups of people and individuals based on ethnicity, race, socioeconomic status, gender, exceptionalities, language, religion, sexual orientation, and geographical area." Therefore, careful consideration of teacher education practices for students with exceptionalities (i.e., disabilities, 
gifted and talented) is needed. The 2002-2003 school year of The National Center for Education Statistics (NCES) found that 3,900,000 students had Individual Education Plans (IEPs), or $8 \%$ of the population in the United States (NCES, 2005).

Teacher educators need to prepare pre-service university students to enter a classroom with the knowledge and resources to work with all school-aged children. Referring to children in preschool through high school environments, Kugelmass (2001) states:

In schools with diverse student populations, poor educational performance is greater among children from low-income, nonEuropean American families than among more affluent and/or dominant culture students. Within these schools, poor and minority children are also over- represented among those classified for special education and placed in separate special education classes. (p. 180)

Thus, teachers struggle to conceptualize the needs of students of different cultural background and/or socio-economic status, which can result in detrimental practices. As such, teacher educators need to enable prospective teachers to be able to enter the classroom and maximize the learning of all children, not just those of similar backgrounds. Recent scholarship on creating inclusive settings provides insight into how teacher educators can establish environments and communities for all children. Once they understand inclusive practices, preservice teachers may not be as profoundly affected by the mismatch between their students' and their own backgrounds.

\section{Academic Structures and Inclusive Practices}

The place of students with disabilities within the curricula of many teacher education programs and in the physical layout of school buildings, from preschools to high school, often appears to be peripheral. Most colleges of education, preschool to high school buildings, and other school structures house programs for these students on the periphery. Housed in attics, basements, and other separate spaces, the physical distance of special education from general education symbolizes the explicit marginalization of students with disabilities. When questions arise concerning the derivation of implicit beliefs about the otherness or lack of understanding surrounding students with disabilities, one possible origin of the maladaptive beliefs is in the structures students participated in during their schooling. When students with disabilities are excluded from the action zones (i.e., typical learning or participant areas) of the school buildings, "normal" comes to be conceived as those activities that take place in the welltraveled school structures. Students with disabilities are perceived as being on the fridge or outside of the regular school facilities because of their physical distance from the regular classrooms.

The distancing of students with disabilities continues in college where special education programs tend to reside outside or separate from traditional, general-education preparation of teachers. The structures inherent in most teacher education programs reinforce the distancing of students with disabilities. For future teachers to be able to conceptualize true inclusive settings, their 
training must be in an inclusive program, involving both general-education and special-education personnel. In essence, it is difficult to discuss and model, for example, co-teaching techniques when students and professors in both general and special education do not participate in similar university classes or activities.

When analyzing inclusive practices in teacher education, Booth, Nes, and Stromstad (2003) write:

The notion of special needs education can involve a simplistic view of the origins of educational difficulties as arising within learners themselves, and can thereby deflect attention from barriers to learning and participation, arising from discriminatory practices, curricula, teaching approaches, school organization and culture and from national and local policies. (p. 4)

As a result, Booth, Nes, and Stromstad argue that attention must shift away from the individual students with disabilities to focus on the structures (implicit and explicit) in our schools that serve as barriers to the inclusion of all students.

Some institutions have begun to find ways to begin this process. For example, some teacher education are beginning to require prospective educators to receive general or traditional licensure as well as special education licensure (Nagata, 2005). This promising practice allows novice teachers to see how special education practices and theories can aid the learning of all students in JK12 settings.

When teacher educators model inclusive practices and establish programs linking traditional and special education, pre-service teachers learn vicariously about the success and necessity of acknowledging the strengths of all students. Uncovering pre-service teachers' beliefs about the embeddedness of special education pedagogies within general education, teacher educators can begin to dismantle the traditionally divisive structures. Teachers' struggles to understand the necessity of including all students in classroom practices stem, in part, from the lack of inclusive models presented when they themselves were students. Inclusion is one initiative that can help to link the traditional and special education programs.

\section{What is Inclusion?}

What is inclusion? Multiple definitions and conceptions of the term inclusion fill textbooks, research articles, and conversations. Much disagreement exists over what inclusive communities are and what inclusion is (e.g., Nagata, 2005; Paul \& Ward, 1996; Thomas \& Vaughan, 2004). It has also been argued that inclusion is closely aligned with accessible instruction or education and is analogous to concepts such as culturally relevant teaching, differentiated instruction, and even the 'zone of proximal development' (Nagata, 2005; Tomlinson, 1995, 1999, 2000).

In 1988, Frontier College in Toronto, Ontario, first used the word, inclusion, to refer to the process in which students and adults were placed in mainstream learning situations (Thomas \& Vaughan, 2004). Since that time, "it [inclusion] has become a slogan--almost obligatory in the discourse of right-thinking people" (Thomas \& Vaughan, 2004, p. iv). A common definition of inclusion 
"emphasizes that students with disabilities should be included in all school programs and activities" (Smith, Polloway, Patton, \& Dowdy, 2006, p. 5). Or: "Inclusion refers to restructuring education provision to promote 'belonging', i.e., all pupils in a school see themselves as belonging to a community, including those with significant disabilities. As such, inclusion embraces the concept of diversity as a natural state of being human or in educational terms, of being a learner" (Avramidis, Bayliss, \& Burden, 2000, p. 278). This definition implies that there needs to be a restructuring of the traditional education model in order to address the multiple aspects of classroom environments influencing the inclusion of all students. As Kennedy and Fisher (2001) describe: "The underlying value behind inclusive education is that all children should be welcomed members of the school, classroom, and larger community" (p. 1).

Another vision of inclusion emphasizes the importance of creating social justice agendas within classroom and school communities whereby teachers accommodate the learning and behaviours of students from different cultures and abilities. In particular, these teachers adopt teaching strategies that serve to construct a learning environment conducive to the academic and social development and inclusion of all students as members of the school community.

Figure 1 illustrates a model for the preparation of prospective teachers to implement inclusive classroom practices (Kugelmass, 2001), which is similar to positive psychological practices. The figure illustrates the multiple facets involved in socializing teachers to enact inclusive practices.

According to the model, the four aspects of the socialization process for preparing teachers for inclusive practices are: curriculum and instruction, social systems, family and community, and the child. Attention is not exclusively placed on the child because inclusion is viewed as a multi-dimensional process. Teacher educators have the responsibility of preparing pre-service students to address all aspects of inclusive education in constructivist or positive psychological environments. In addition, the extensive knowledge of assessment, collaboration, instructional strategies and belief systems sets up a rather complex situation.

In essence, the goal of teacher educators must be to train pre-service teachers to envision the potential in all students to obtain the knowledge and skills needed to develop into positive and productive citizens. In particular, teacher educators must encourage pre-service teachers to reflect on their own knowledge and beliefs about students with disabilities (Gabel, 2001). Through the reflective process, any previously subconscious mistruths, prejudices, and/or stereotypes may surface, and conversations can begin to refocus the future teachers in more positive directions. By bridging the traditional binary between general and special education, teacher educators model inclusive practices. 


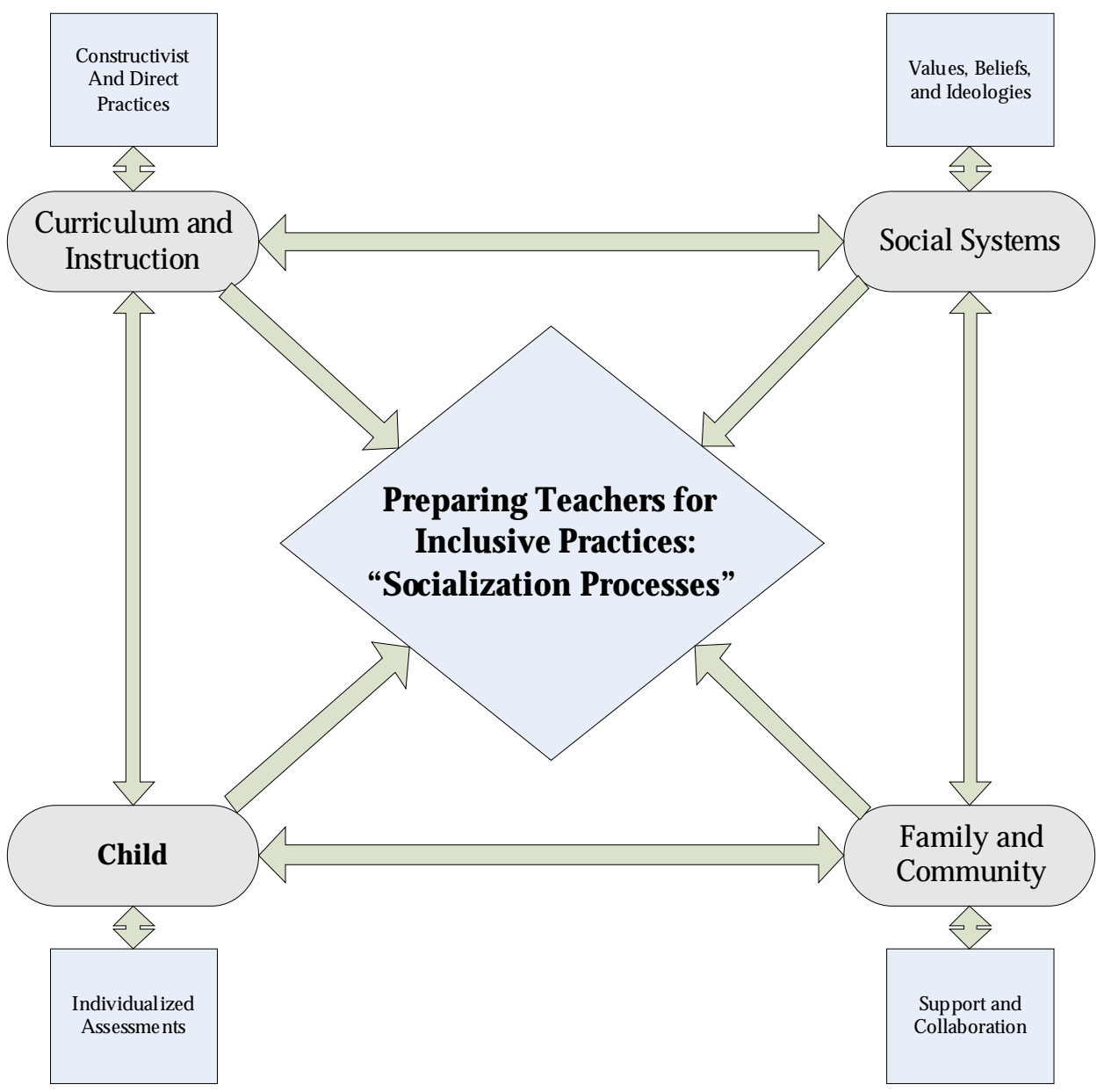

Figure 1. Preparing Teachers for Inclusive Practices

\section{Bridging the Divide}

How do we create a bridge to cross the divide between general education and special education programs? It can be argued that the "divide" is due to several factors, such as separate "education/training" programs, research agendas, and instructional practices-all of which are influenced by underlying frameworks. To empower pre-service teachers with the knowledge and disposition towards constructivist or positive psychological practices, it is critical to make them aware of two broad, dichotic paradigms that are often used by teacher educators (Alton-Lee, Reitveld, Klenner, Dalton, \& Town, 2000), which are similar to those used by researchers/scholars (Paul \& Ward, 1996). First, the paradigm of Personal Tragedy aligns teachers' beliefs with the notion that the disability is located within the individual, and requires fixing. In so doing, teachers approach students with disabilities from a deficit perspective as they strive to correct or modify the disability. In this paradigm, teachers focus attention on the students' disability and not the strengths of every student (see also, the comparison paradigm in Paul \& Ward, 1996). Pugach and Seidl (1995) argue that the traditional model of disability—-termed a medical or clinical model —is based on 
the notion of a single fixed reality, which presumes a "norm" or one correct (or average) pattern for assessment and development. Thus, when comparisons are made with children with disabilities, the "differences" are often viewed as "deficiencies", especially if they are one or two standard deviations below the norm.

The second paradigm that many teacher educators use is the Social Constructivist paradigm (Alton-Lee et al., 2000; see also, the ethical paradigm in Paul \& Ward, 1996). Using this framework, teacher educators encourage preservice teachers to uncover the social context that creates barriers and limitations for equal participation. Once the pre-service teachers enter the profession, they have the knowledge and skills to enlist the entire community in the creation and maintenance of inclusive practices. In so doing, the entire community celebrates student differences and does not view differences as deficiencies.

Understanding the implications of these broad paradigms should contribute to the understanding of educational practices, for example, the manner in which standardized testing procedures are used to assess student, teacher, and school effectiveness (Wood, 2004). This "assessment" system perpetuates the deficit perspective of students with disabilities (Shields et al., 2005). Using the bellshaped curve to describe human potential, many students with disabilities fall below average, and educators conclude that their task is to correct students' weaknesses (Weinstein, 2002).

With respect to differential terminology, in the United Kingdom children are said to have needs, whereas students in the United States are labeled as having disabilities (Thomas \& Vaughan, 2004). In the United States, this preoccupation with labels of weaknesses encourages teachers to look at what is wrong with students with disabilities instead of focusing on the strengths and contributions of all students (Feiler \& Gibson, 1999). This tendency is furthered when considering readings and textbooks used in teacher education. In an analysis of texts in general education and special education, Sapon-Shevin and Zollers (1999) discuss the organization of textbooks used in special education, many of which tend to create categorical models. The authors observe that pre-service teachers are trained to conceptualize students by disability and are presented with models of how to "correct" the students.

The "divide" can also be seen in the lack of a unified program, a set of common experiences, and a shared agenda. For example, Tom (1997) mentions, "Departmentalization has a negative impact on teacher education, because the faculty members working in teacher education usually come from three or four departments, each of which views itself as the final arbiter of the content in its specialized areas" (p. 5). Sapon-Shevin and Zollers (1999) discuss the history of separate agendas in teacher education. General education and special education majors tend to be distinct in nature; general education programs include a course on what it means to facilitate an inclusive classroom whereas special education programs tend to learn how to describe and prescribe how to work with all children (Sapon-Shevin \& Zollers, 1999). As such, the two programs have different content and pedagogical choices. Therefore, prospective teachers receive very different educations based on whether they enroll in a traditional or a special education program. 
It should be clear that a single university course on inclusion or even an introductory course in "special education" (Nagata, 2005) cannot adequately prepare teachers to successfully implement the various aspects of inclusive practices. There is a need to develop a well planned program of courses and experiences in both general and special education wherein students have opportunities for collaborative endeavors that reflect what occurs in authentic school situations. The need to involve teachers from the field is also important so that in-service teachers can provide a wealth of relevant experiences for university students.

Ainscow (1997) asks: "Are we aiming for a unified system of schooling that is capable of responding to all children as individuals, or are we going to continue with the tradition of parallel systems whereby some children receive separate forms of education?" (p. 3). Arguably, the systems will remain parallel until we prepare our novice teachers to cross the divide and enable general and special education teachers to work in tandem. Before crossing the divide, a structure to justify and support inclusive practices must be built. In particular, teacher educators must believe in the importance of inclusive practices and be able to support all students in twenty-first century classrooms.

We believe that both types of expertise (general education and special education) are needed; however, we are unconvinced of the need for distinct, parallel programs. In our view, all pre-service teachers need a "generaleducation" background and a modicum of knowledge about the various disabilities of children and adolescents, including the effects of these disabilities on learning. There will be a need for more in-depth knowledge about individuals with particular disabilities; however, this should not be within a traditional "special education" paradigm. Rather, this should occur within an intervention specialist paradigm where this person would participate in co-teaching situations. Thus, both teachers would have a general education background, but one of them would have more extensive knowledge of working with children and adolescents with specific disabilities.

In order for this model to work, the $\mathrm{JK}$ to $12^{\text {th }}$ grade licensure programs for intervention specialist programs (in the United States) needs to be reconceptualized. For example, individuals may have experience working with students with particular disabilities (hearing impaired, etc.) within the $\mathrm{JK}$ to $12^{\text {th }}$ grade range, but may only have 'content' knowledge within one of the generaleducation ranges (early childhood, middle childhood, or adolescents/young adults [AYA]). In fact, this is the intent of the controversial Highly Qualified Teachers (HQT) issue (No Child Left Behind [NCLB] 2002) that is occurring in the United States. For example, if an intervention specialist is the teacher of record for students in the high school area, then the specialist must have competence in the content area (physics, etc.) under consideration. If the specialist is the instructor of record for all content areas in high school, then there is the impossible situation of having content knowledge in all areas. It appears that coteaching situations need to be considered within any inclusive model. It might be that there needs to be two teachers for inclusive classrooms involving students with and without disabilities.

Recent scholarship on inclusive environments solidifies the need to maximize the strengths of all students in a classroom. Inclusive classroom 
practices have been linked to increased social affiliation and learning opportunities for students with disabilities (Kennedy \& Fisher, 2001; Kluth et al., 2003; Nagata, 2005). For example, Rex (2000) used case study methods to investigate inclusive practices in general education classes. Following one student classified with learning disabilities, Rex (2000) found that including the student (Judy) within the classroom culture did not limit the other students' learning opportunities, while allowing for Judy to experience academic and social success. There seems to be evidence for the benefits of inclusion, especially if the entire school or community adheres to this value (Kugelmass, 2001; Nagata, 2005). Yet, whether or not inclusion is necessary and needed in schools falls upon one's moral decision making. If one believes that all children should have equal access to education, policies should be made to enact such practices.

In defense of giving all students access to high quality education experiences, Biklen (1985) argued for the mainstreaming of all students. His vision of mainstreaming is aligned with our conception of inclusion in 2005. To defend including all students in JK-12 schools, he remarked, as indicated in Thomas and Vaughan (2004):

Asking the question: 'Is mainstreaming a good idea?' is a bit like asking: 'Is Tuesday a good idea?' Both are wrong questions. It's not so much whether mainstreaming and Tuesday are good ideas as what we make of them. In the past three years we have visited more than one hundred schools across America. In more than two dozen we have observed school life and particularly, mainstreaming intensively. As we could easily have predicted, we have seen good and bad mainstreaming. Just as we can look back on all the Tuesdays in our lives and say, "There have been good ones and bad ones," we can also see that mainstreaming can succeed or fail. Therefore, to ask, "Does it work?" is also to ask the wrong question. (p. 72)

Thus, including students of all ability in classrooms should not become a question of choice. All students have the right for equal access to educational opportunities. For inclusive practices to be successful, teachers must have the knowledge and skills to make such practices effective (Tomlinson, 1995, 1999, 2000; Tomlinson, Kaplan, Renzulli, Purcell, Leppien, \& Burns, 2002).

\section{Preparing Teachers to Work in Inclusive Settings}

What can be done to encourage the use of more inclusive perspectives in university teacher education programs? Since 1839 when Horace Mann required teachers to receive special preparation, many debates have focused on how to best prepare prospective teachers (Cruickshank, 1996). At present, questions arise concerning what general and special educators need to know to create inclusive classroom settings (Kluth et al., 2003; Nagata, 2005; Paul \& Ward, 1996). How do special educators provide open communication networks that enable general and special education teachers to work together, create, and/or support children in inclusive classroom settings? Are both groups trained in the use of collaborative or co-teaching techniques? Do "general educators" have 
sufficient knowledge, skills, and dispositions to work with children with varying levels of abilities?

Scruggs and Mastropieri (1996) found that two-thirds of teachers agreed with concepts of integration/inclusion, yet only a third of the teachers believed they had sufficient resources to create inclusive settings. In addition, Avramidis et al. (2000) surveyed prospective teachers' beliefs about inclusion and found a general lack of confidence in their ability to meet the requirements of Individualized Education Plans (IEPs). Furthermore, Richards and Clough (2004) found that pre-service teachers believed that inclusion would not influence or affect them personally. Research on prospective teachers has found that novice educators believe inclusion to be a positive practice, yet they do not believe they are capable of implementing inclusive practices in their classrooms, nor do they believe they will be asked to do so. These findings allow us to understand that pre-service teachers, in general education, are capable of defining inclusion, yet they struggle to enact true inclusive practices (Beyer, 2001; Nagata, 2005).

As Tom (1997) recalls: "My overall teacher education program had little effect on my beliefs about the nature of subject matter, not even fostering selfawareness of these beliefs" (p. 111). Teacher educators must ensure that the context of teacher education programs prepares pre-service teachers to maximize the learning of all students. Yet, according to Tom: "Education courses are vapid, impractical, segmented, and muddled" (p. 45). Therefore, effective general teacher educators must create practical and cohesive program structures that focus on inclusive practices. To do so, teacher educators should begin by challenging the conception that inclusive education is just another burden teachers encounter when they enter the classroom.

For many years, scholars have questioned how to change the burden mindset of inclusive practices to a welcoming/enriching notion (Tredgold, 1952). Such notions are represented by statements such as: "Instructors face substantial challenges when their classes include students with disabilities, especially those that affect communication" and: "Teaching students with disabilities requires considerable effort on the part of instructors" (Dominowski, 2002, p. 154). In comparison, a text might begin with the notion that every student who enters the classroom brings complex strengths and weaknesses; that the teacher's challenge is to maximize the strengths and decrease the weaknesses.

How do we proceed to enact practices that value all students equally? Teacher educators are charged with the task of assisting students in developing personal agency for creating effective, inclusive environments. In particular: "Preparing teachers to work in equitable ways within inequitable educational systems requires developing new teachers' beliefs in their own power to effect change" (Kugelmass, 2001, p. 179).

Many successful strategies can be implemented to encourage prospective teachers to take activist agendas toward creating inclusive classroom environments. Some successful practices include the use of autobiographical storytelling, personal myths, and visual imagery. For example, a pre-service teacher program uses structured fieldwork experiences and charges prospective teachers with the task of interviewing the community regarding Downs Syndrome (Campell, Gilmore, \& Cuskelly, 2003). In so doing, not only did preservice teachers' beliefs about students with Down Syndrome change, but so too 
did their beliefs about inclusive environments in general. Such research provides one strategy for encouraging pre-service teachers to challenge traditional notions of peoples with disabilities.

Other successful teacher education programs include the use of action research projects to encourage novice educators to conceptualize creating inclusive communities (Cockrell et al., 1999). In addition, pre-service teachers trained in SCREAM procedures (Mastropieri \& Scruggs, 1997) learned how to create structure, clarity, redundancy, enthusiasm, appropriate rate, and maximal student engagement. This program is just one example of how to scaffold novice educators for successful classroom practices.

When completing a literature review on teacher education and inclusive practices, most articles discuss the struggles to change pre-service teachers' beliefs and concepts aligned with the deficit model (Nagata, 2005). Future research and education coursework must consist of positive examples of successful practices in teacher education. In particular, we must create visions of positive psychological practices for all students.

By adopting a positive psychological framework, teacher educators can challenge the notion that only a singular norm should be used to compare and contrast all students (Baglieri \& Knopf, 2004). Clearly, it is critical to do whatever possible to "improve" the skills (reading, writing, etc.) and physical constitution (speech, hearing, etc.) of students with disabilities. At the very least, this requires an understanding of the effects of the disability on learning-one of the goals of special education. However, the student with disability should not be viewed as deficient when compared to a student without disability. This deficit perspective is, indeed, socially constructed and often prevents the meaningful inclusion of students with disabilities. In essence, all students should be viewed as having 'needs' with some students having more extensive needs than others. Regardless of the needs, there should be attempts to create a positive learning environment for all students.

\section{Conclusion}

There are numerous published works on how to create effective inclusive settings (e.g., see discussions in Kennedy \& Fisher, 2001; Nagata, 2005; Smith et al., 2006; Tomlinson et al., 2002). In addition to employing positive psychological techniques, it is clear that teachers, including special education teachers, need to have knowledge of content and best practices. All teacher educators should begin with Sapon-Shevin and Zoller's (1999) three recommendations:

1. Keep talking

2. Explore joint or collaborative teacher education programs

3. Embrace critical perspectives on disability

In sum, general and special education teacher educators should create structures that envision a community where differences in abilities are understood and conceptualized. Teacher educators possess the power to develop positive psychological learning communities for all students. As researchers and scholars, there are incredible opportunities to delve further into notions of positive practices of teacher educators. Maximizing the collaboration of 
individuals in both general and special education programs is one step towards more desirable academic and social results for all students.

\section{References}

Ainscow, M. (1997). Toward inclusive schooling. British Journal of Special Education, 24(1), 36.

Alton-Lee, A., Reitveld, C., Klenner, L., Dalton, N., \& Town, S. (2000). Inclusive practice within the lived cultures of school communities: Research case studies in teaching, learning, and inclusion. International Journal of Inclusive Education, 4(3), 179-210.

Avramidis, E., Bayliss, P., \& Burden, R. (2000). Student teachers' attitudes toward inclusion of children with special educational needs in the ordinary school. Teaching and Teacher Education, 16, 277-293.

Baglieri, S., \& Knopf, J. H. (2004). Normalizing difference in inclusive teaching. Journal of Learning Differences, 37(6), 525-529.

Beyer, L. (2001). The value of critical perspectives in teacher education. Journal of Teacher Education, 52(2), 151-163.

Biklen, D. (1985). Achieving the complete school: Strategies for effective mainstreaming. New York: Teachers College Press.

Booth, T., Nes, K., \& Stromstad, M. (2003). Developing inclusive teacher education. London: Routledge Falmer.

Campell, J., Gilmore, L., \& Cuskelly, M. (2003). Changing student teachers' attitudes toward disability and inclusion. Journal of Intellectual and Developmental Disability, 28(4), 369379.

Cockrell, K. S., Placier, P. L., Cockrell, D. H., \& Middleton, J. N. (1999). Coming to terms with 'diversity' and 'multiculturalism' in teacher education: Learning about our students and changing our practices. Teaching and Teacher Education, 15, 351-366.

Cruickshank, D. (1996). Preparing America's Teachers. Bloomington, IN: Phi Delta Kappa Educational Foundation.

Dominowski, R. (2002). Teaching undergraduates. Mahwah, NJ: Lawrence Erlbaum Associates.

Feiler, A., \& Gibson, H. (1999). Threats to the inclusive movement. British Journal of Special Education, 26, 127-151.

Gabel, S. (2001). "I wash my face with dirty water" Narratives of disability and pedagogy. Journal of Teacher Education, 52, 31-47.

Gay, G., \& Howard, T. (2000). Multicultural teacher education for the 21st century. The Teacher Educator, 36(1), 1-16.

Kennedy, C., \& Fisher, D. (2001). Inclusive middle schools. Baltimore, MD: Brookes.

Kluth, P., Straut, D., \& Biklen, D. (2003). Access to academics for all students: Critical approaches to inclusive curriculum, instruction, and policy. Mahwah, NJ: Lawrence Erlbaum Associates.

Kugelmass, J. (2001). Subjective experience and the preparation of activist teachers: Confronting the mean old snapping turtle and the great big bear. Teaching and Teacher Education, 16, 179-194.

Ladson-Billings, G. (2001). Crossing over to Canaan: The journey of new teachers in diverse classrooms. San Francisco: Jossey-Bass.

Mastropieri, M., \& Scruggs, T. (1997). What's special about special education: A cautious view toward full inclusion. The Education Forum, 61, 206-211.

Milner, R. (2005). Stability and change in US prospective teachers' beliefs and decisions about diversity and learning to teach. Teaching and Teacher Education, 21, 767-786.

Nagata, N. (2005). Characteristics of teacher preparation programs and the issue perceptions of teacher educators in deaf education. Unpublished doctoral dissertation. The Ohio State University, Columbus.

National Center for Education Statistics (NCES). (2005). The condition of education. Washington, DC: Institute of Education Sciences, U.S. Dept. of Education. Retrieved November 30, 2005, from http://nces.ed.gov/programs/coe/

National Council for the Accreditation of Teacher Education. (2002). Professional standards for the accreditation of schools, colleges, and departments of education. Retrieved September 4, 2004, from http://ncate.org/standards/unit-stds.htm 
No Child Left Behind. (2002). No Child Left Behind Power Point Presentation. Retrieved September 22, 2004, from http://www.ed.gov/nclb/overview/intro/index.html

Paul, P., \& Ward, M. (1996). Inclusion paradigms in conflict. Theory into Practice, 35(1), 4-11.

Peterson, C., \& Seligman, M. (2004). Character Strengths and Virtues: A Handbook of Classification. New York: Oxford University Press.

Pugach, M., \& Seidl, B. (1995). From exclusion to inclusion in urban schools: A new case for teacher education reform. Education and Urban Society, 27, 379-395.

Rex, L. (2000). Judy constructs a genuine question: A case for interactional inclusion. Teaching and Teacher Education, 16, 315-333.

Richards, G., \& Clough, P. (2004). ITE students' attitudes to inclusion. Research in Education, 72, 77-87.

Saft, E., \& Pianta, R. (2001). Teachers' perceptions of their relationships with students: Effects of child age, gender and ethnicity of teachers and children. School Psychology Quarterly, 16(2), 125-141.

Sapon-Shevin, M., \& Zollers, N. (1999). Multicultural and disability agendas in teacher education: Preparing teachers for diversity. International Journal of Leadership in Education, 2(3), 165190.

Scruggs, T., \& Mastropieri, M. (1996). Teacher perceptions of mainstreaming/inclusion, 19581995: A research synthesis. Exceptional Children, 63, 59-75.

Seligman, M., \& Csikszentmihalyi, M. (2000). Positive psychology. American Psychologist, 55(1), 5-14.

Shields, C. M., Bishop, R., \& Mazawi, A. E. (2005). Pathologizing practices. New York: Peter Lang.

Smith, T., Polloway, E., Patton, J., \& Dowdy, C. (2006). Teaching students with special needs in inclusive settings. Boston: Allyn and Bacon.

Thomas, G., \& Vaughan, M. (2004). Inclusive education: Readings and reflections. New York: Open University Press.

Tom, A. (1997). Redesigning Teacher Education. Albany, NY: State University of New York Press.

Tomlinson, C. A. (1995). How to differentiate mixed-ability classrooms. Alexandria, VA: Association for Supervision and Curriculum Development.

Tomlinson, C. A. (1999). The differentiated classroom: Responding to the needs of all learners. Alexandria, VA: Association for Supervision and Curriculum Development.

Tomlinson, C. A. (2000). Reconcilable differences: Standards-based teaching and differentiation. Educational Leadership, 58, 6-11.

Tomlinson, C. A., Kaplan, S. N., Renzulli, J. S., Purcell, J., Leppien, J., \& Burns, D. (2002). The parallel curriculum: A design to develop high potential and challenge high-ability learners. Thousand Oaks, CA: Corwin Press.

Tredgold, A. F. (1952). Mental Deficiency. London: William Wood.

Weinstein, R. (2002). Reaching higher: The power of expectations in schooling. Cambridge, MA: Harvard University Press.

Wood, E. (2004). A new paradigm war? The impact of national curriculum policies on early childhood teachers' thinking and classroom practices. Teaching and Teacher Education, 20, 361-374. 